\title{
Dress aesthetics of smock in northern Ghana: form, function, and context
}

\begin{abstract}
The paper is a study of the dress aesthetics of smock in Northern Ghana; their form, function and context. The study examines the cultural aesthetics of smock in Northern traditional textiles and its role in the preservation, presentation and promotion of Northern culture and makes recommendations for its sustenance. The researchers adopted the qualitative paradigm and used descriptive and visual analytic approaches through the use of interviews and observations as its research tools.
\end{abstract}

Keywords: aesthetic, artefacts, cultural symbolism, indigenous textiles, regalia, smock, north, traditional rulers, yensichi, dagomba, bingmaa, kpakoto, yeble, balmaasu, kuyilli gbagno, moslem community, nam-kpaargu
Volume I Issue 2 - 2017

\author{
Samuel Acquaah,' Emmanuel RK Amissah, ${ }^{2}$ \\ Patrique de Graft Yankson ${ }^{3}$ \\ 'Department of Education, Ghana Museums and Monuments \\ Board, Ghana \\ ${ }^{2}$ Department of Textile Design and Fashion Studies Education, \\ University of Education, Ghana \\ ${ }^{3}$ Department of Graphic Design, University of Education, Ghana
}

Correspondence: Emmanuel R K Amissah, Department of Textile Design and Fashion Studies Education, University of Education, PO Box-25,Winneba, Ghana, Tel 23320505I848, Email erkamissah@gmail.com

Received: November 23, 2016 | Published: March 15, 2017

\section{Background to the study}

Dress and other facets of body art have always had a strong role in protecting the histories, values and ethnic identities of many cultures. This is true of all art forms, yet body arts evidence fine distinction through changes of status linked with rites of passage or temporary display roles for ritual occasions, as well as personal affiliations and preferences which are less manifest in more impersonal artefacts. The communicative, expressive, and symbolic nature of dress in Ghana indicates a person's identity or status, whether young or old, Northerner or Southerner, leader or commoner. The artistic properties and styles of dress and personal decoration are of great concern. Clothing is one of the commonest media of expressing Ghanaian symbolic art. ${ }^{1}$ The Smock is the most distinctive dress from Northern Ghana. The Smock by design is shaped like the "dondon" drum of the Dagombas; two ends are broader with trimmer middle which when stitched together makes a beautiful dress. Smock as we have it today has seen many evolutions and adaptations to suit the various uses they are envisioned. ${ }^{2}$ Since it was introduced into Dagbon during the reign of the Ya-Naa Zangina, Smock has evolved from royal wear on communal occasions to casual and official wear to suit many situations in life. ${ }^{3}$ Smock has fascinating colour stripes arranged in a rhythmic order. The beauty of Smock is seen when men do the "damba" dance with the edge of the dress going round in circles. ${ }^{4}$

In Northern Ghana, Smock (fugu) production centres are among the following ethnic groups: the Moshie, Kokomba, Dagomba, Mamprusi, Lobi, and Gonja, however, none of these can claim originality of the art in Northern Ghana. Northern tradition maintains that the Smock fabric was introduced into the region by the Moshie from Ouagadougou. They were believed to have come into contact through trade to the North from the Upper Volta in exchange of woven pieces for kola nuts, millets, yam, rice, guinea fowl and other foodstuffs. ${ }^{5}$ Some of the main weaving areas are Bolgatanga, Daboya, Tamale, Gushegu, Kpatinga, Yendi, Bawku and Navrongo. Studying the production, aesthetics, form, function, and context of Smock from Northern Ghana and its role in the preservation, presentation and promotion of Northern culture remain paramount in deepening scholarship of Ghana's ethnic textile heritage.

\section{Purpose of the study}

The study sought to identify the types, production and analyse the concepts of aesthetics of smocks in Northern Ghana and to also examine the role of Smock in preserving, presenting and promotion of Northern Ghanaian cultural identity.

\section{Research questions}

a. What are the types and aesthetics that can be identified in wearing smocks?

b. How are smocks produced?

c. What role does Smock and its fabrics play in the promotion of Northern culture?

\section{Methodology}

\section{Research design}

The descriptive research methodology was utilised in this study that surveyed smock dealers, producers, cultural officers and traditional authorities from the Northern part of Ghana. Its usage in the study allowed for detailed description and exploration that provided better in-depth understanding of smock.

\section{Research instrument}

The researchers made use of observations and interviews as data collection instruments for the study. Structured interview with the general interview guide approach was adopted for the research. The guide approach was intended to ensure that the same information was collected from each interviewee. This provided more focus, but still allowed a degree of freedom and adaptability in getting the information from the interviewee. Structured interview ensured that consistent data was compared across a number of respondents. 


\section{Population and sampling technique for the study}

The population of the study constituted the Traditional rulers and family heads, producers of Smock and the general public from the Northern part of Ghana. In conducting the interviews, the purposive random sampling technique was employed. The various groups of people interviewed and traditional weaving centres and shops visited were all selected from the Northern part of Ghana. Among the places resorted for interviews were Daboya and Tamale in Northern region, Navrongo and Bolgatanga in the Upper East region and Wa in the Upper West region. The population was divided into six strata of respondents; Traditional rulers, family heads, producers of Smock, the general public, distributors of Smock and its fabrics and recognized elders knowledgeable about the aesthetics of Smock and traders of these products were consulted. In all, one hundred and fifty (150) respondents were selected from the population. This made up of forty (40) Traditional Rulers, fifty (50) Producers, forty (40) General Public and twenty (20) Distributors.

\section{Results and discussion}

\section{Data analysis plan}

The data analysis was done by content analysis manually, on the basis of data collected from the interviews, observations and the field notes. The discussions, results and appreciation of smock and smock-products and their relevance to the promotion of Northern and Ghanaian cultural identity has been presented sequentially in addressing the research questions and grouped to reflect the topical issues identified in the study.

\section{Types and concepts in aesthetics of smock}

Colours generally seen in smock fabrics are formed by the warp pattern of the cloth. ${ }^{6}$ According to $3 \%$ of the total number of respondents, the beauty of smock depends on the colour distribution and compactness of the weave, but the remaining $97 \%$ of the total respondents posit that the beauty of the smock is equated with significance, purpose or function of the dress. They observe that beauty is not always considered in terms of physical qualities such as the colours used in weaving the smock. Therefore the aesthetic values attributed to smocks have to do with their significance, purpose or functionality. The following types of smock and their aesthetics were collaborated by $100 \%$ of the respondents.

Yensichi/densikyi: The respondents posit that the name is of Hausa origin, literally meaning a single or something worn to cover the bare skin or an under shirt. This type of smock is sleeveless and the pockets are at the sides. It can be made from hand woven fabric and hand sewn or machine made by a tailor. This type of smock is the commonest because of the purpose it is used for. It can be casual wear or to be worn as a single before a bigger smock. It is usually smaller and it is not supposed to be seen protruding underneath. The pockets of Yensichi are at the sides. The length of a smock is usually the same length as the wearer's trouser length in that way the pleats fall on the waist line of the wearer. In such a position, the smock dances by itself when the person moves at a normal pace. Yensichi is worn by all manner of persons in the society due to its nature of allowing free air to circulate in the heat of the Savannah sun. The neck is either circular or circular with a split in the front giving it a guard shaped appearance. A typical Dagomba Yensichi is not embroiled at the neck, but hand stitched in terms of decoration. The embroidery differentiates a Dagomba smock from other types worn by the people of the Upper East and West Regions (Figure 1).

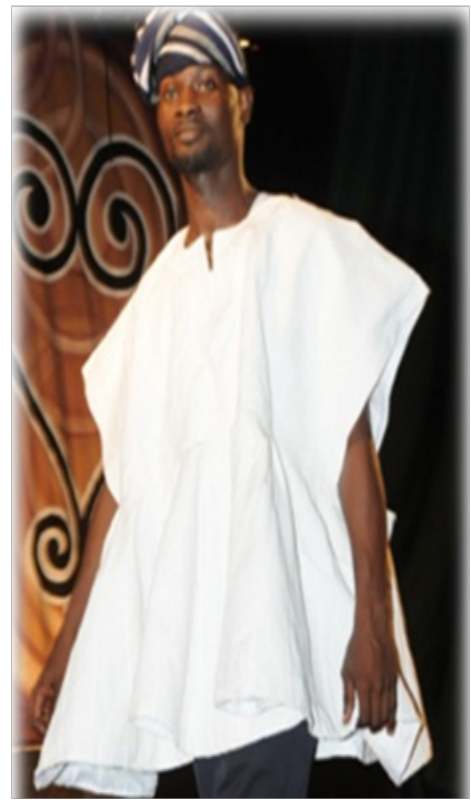

Figure I A man in Yensichi.

Bingmaa: Bingmaa is a Yensichi with sleeves. This is the smock usually used in dancing. Its sleeves extend to the elbow with a neck either circular or split opened at the front. It is usually hand stitched and decorated. The length flows to the midsection of the thigh of the wearer. Its length is the same as the length of the wearer's trouser length. In that way, the gathers or pleats starts from the waistline. A wearer with the sleeves below the elbows and the length down to the knees exposes the wearer as wearing a borrowed dress or inherited from parents. Pockets are on the front and also hand stitched. The respondents indicated that Bingmaa literally means "short one" in Dagbani. This means it also has to be worn under another dress, possibly the Kpakooto or Yebli. Traditionally Bingmaa is for royalty. However the perception has changed over the years with wealth and education, having changed people's social status. It is now a matter of affordability. The length or size of it has not changed, so any Dagomba worth his salt will always prefer to wear one which is well tailored to fit. In this way, craftsmen are usually, pre-financed when placing an order to suit ones taste and size. It is the uniform that is usually worn on festive occasions such as festivals, funerals or when visiting inlaws (Figure 2).

Kpakoto: Kpakoto has the same appearance as the Bingmaa except its sleeves are bigger and longer. The sleeves stretch from the shoulders to the wrist. The length also extends to below the knees. It is normally worn over the Bingmaa (which is also worn over the Yensichi) and should completely cover the Bingmaa without trace. The neck is either circular or with a split in front. It can be embroiled with a machine or hand stitched. It also has its pockets in front in a vertical position. Traditionally, it belongs to the royalty and the rich in society. It is usually worn on Mondays and Fridays by Chiefs when they sit in the state to receive homage from their subjects. When used on festive occasions, there is a clear difference as to the social status of the wearer. A Chief (Naa) wears his in a Show-off fashion; he does not fold the sleeves and walks majestically (Figure 3). A Prince (Nabia-yong) who has not yet ascended to any title wears his 
by folding the right hand sleeve over his shoulder while leaving the left flowing downwards, like a peacock in the making. A commoner (Tarim) whose economic status can afford it wears his while folding both sleeves over his shoulders. One can see that there is a structured social differentiation in the wearing of this type of smock. The rules are strictly enforced in the traditional areas and a break of these rules may attract a heavy sanction or spell doom for the offender especially during festive occasions (Figure 4). During festive occasions when a gorgeous Dagomba man is dancing, one will notice when he swings his dress, that there may be other colours underneath. It implies that the dancer has a Yensichi, Bingmaa and a Kpakoto on. In that three piece attire, the wearer has a personality of royalty (Figure 5).

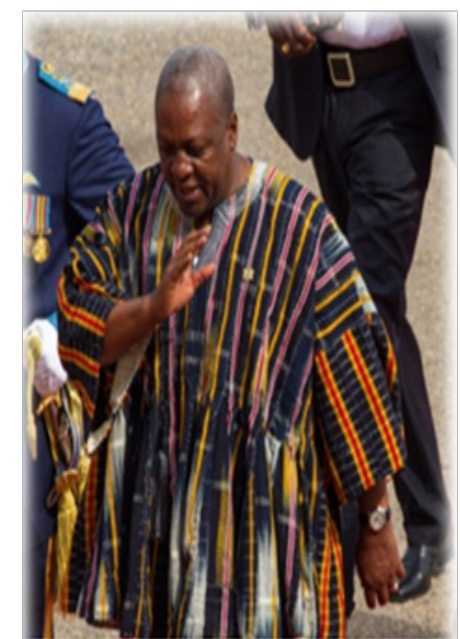

Figure 2 President John Dramani Mahama (President of the Republic of Ghana) in Bingmaa during the Independence Day celebration on 6th March, 2016.

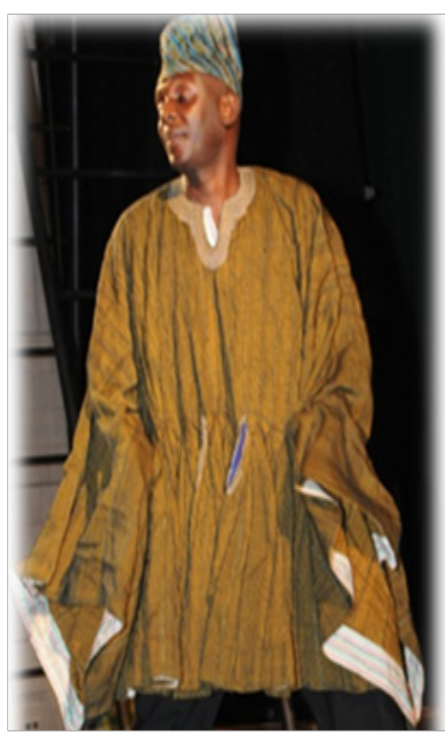

Figure 3 Kpakoto in "NAM" (ROYAL) Peacock Posture.

Yable/yabli: Yable is almost the same as the Kpakoto in terms of design and length, with the difference showing perhaps in the decorated embroidery at the front and the back of the neck. Another distinct feature is that Yeble is given a type of V shaped neck, a large pocket flap which extends to the lower stomach on the left side from the tip of the neck embroidery. It is sometimes slightly larger and wider in outlook than the Kpakoto. The Yeble smock comes in two variations the Gonja/Wala and that of the Dagomba. The latter is less colourful though decorative, whiles the former places emphases on bright colours. Unlike the Gonjas where Yabli features prominently in every important occasion giving it a near casual status, in the case of the Dagombas, it is the preserve of royalty and tradition. However, this traditional perception has changed over time and it is now the issue of affordability. It is however still worn on special occasions. Like the Kpakoto, Yebli when used on those festive occasions the social differentiation is clearly observed. A chief (Naa) would always wear his with the hand flowing freely as he takes majestic steps. A prince would wear his with the hands of the right side folded over his shoulders, while a commoner would also have all the hands of the smock folded over his shoulders (Figure 6-8).

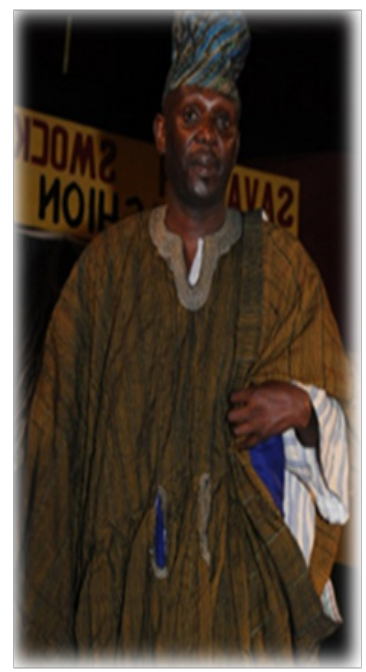

Figure 4 Kpakoto in Prince (Nabia-yong) posture.

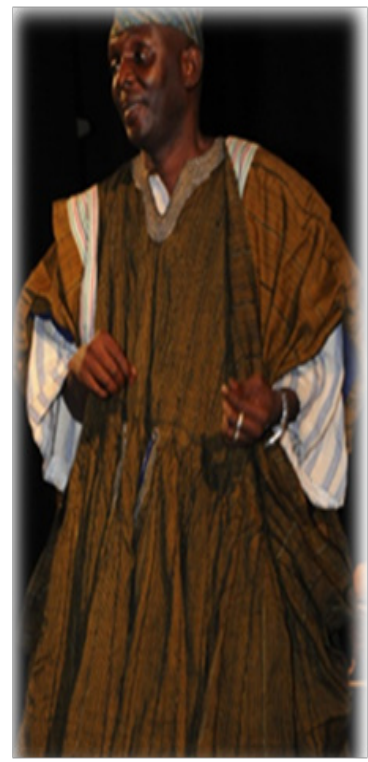

Figure 5 Kpakoto in commoner (Tarim) posture.

Barimasu/balmaasu: Balmaasu is the traditional wear of cavalrymen of Northern Nigeria. It is worn typically by the Hausa and Fulani warriors. The name Balmaasu is an adulterated word from the Hausa expression "Balimashi" meaning give me my spear. The dress itself 
signifies bravery. It was adopted by Dagomba cavalryman when horses were introduced into Dagbon from Hausa land. This smock is a straight dress with fewer pleats and is not too gorgeous. It has a round shaped neck and slightly longer slit at the neck to allow a free hand access to the hidden pockets to draw daggers or swords while in battle. It has thicker lining to let it hold weapons. As a gown, it is almost like a Priest's cassock which touches almost at the ankle level with a central split at the lower end. This spilt is to allow for easy movement and for saddling horses. The sleeves are long, but loose. Traditionally the "Kpaan-kobga" (Guinea fowl) material is used in making the dress, however, due to the dwindling nature of the role of the cavalrymen in Dagbon, the dress is seldom seen and even those in existence are often made from any material one likes. It should be noted however that this dress is not produced for the market; it is made only upon request. There are people in Dagbon in their sixties (60's) who have never seen this dress (Figure 9).

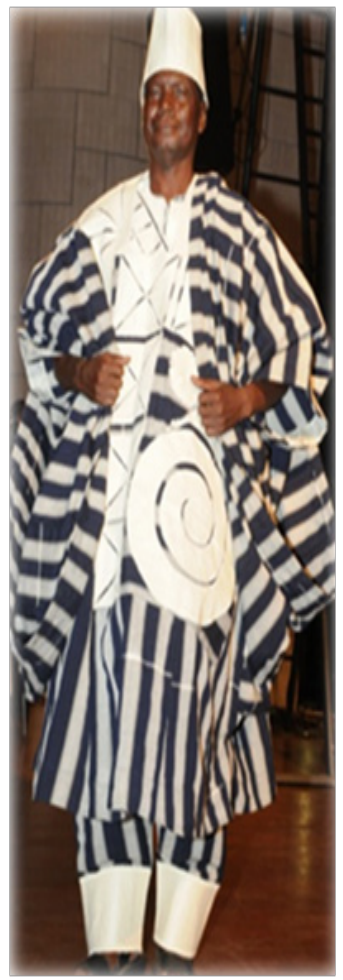

Figure 6 Yable in commoner posture.

War/funeral dress ("Gbagno"): Gbagno as a traditional dress comes in different forms. There is a smaller version without sleeves, no embroidery, which is worn either under another gown as a singlet or alone. It is a wardress by all standards. It is Dagban's version of the "bullet-proof" vest. It is bathed in charms and spiritually fortified to protect the wearer. It may have Arabic inscriptions and talismans on it and sometimes amulets are sewn unto it. It is not a fashionable dress; it is only worn on serious occasions in times of wars or on funeral occasion for protection. It is normally prescribed for a particular wearer and even a son or grandson who inherits one should know its dos and don'ts or one may be endangering one's life in such instances. The new owner would have to perform certain rites before he is empowered to wear it (Figure 10). The other Gbagno is like the Bingmaa but usually with less pleats or gathers for ease of movement. The only difference between the Bingmaa and the
Gbagno is that the latter is fortified and have amulets, talismans and or Arabic inscriptions and worn only on serious occasions and not for fun. The funeral Gbagno ("Kuyilli-Gbagno") is reserved for the heir of the deceased and is worn during final funeral rites of the deceased usually the landlord. The Kuyilli Gbagno is to ward-off evil intentions of "bad people" who might not want the family to have a successful funeral ceremony or those who might think that the heir "Gbaglana" is a potential threat to a skin that his father was occupying. The main difference between the war Gbagno and funeral Gbagno is that war Gbagno is usually small for ease of movement and with Arabic inscriptions and talismans stitched on to it while the funeral Gbagno is bigger with a lot of stitches without talismans.

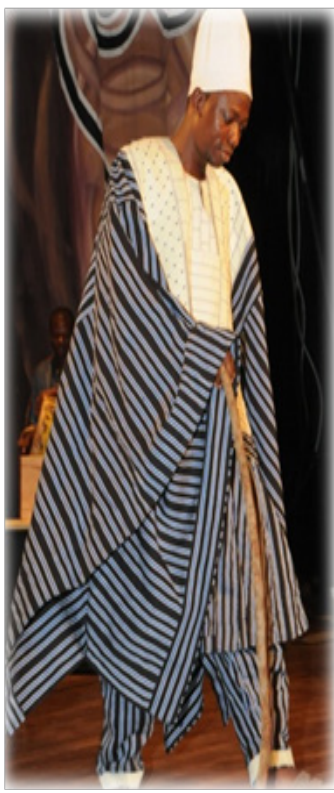

Figure 7 Yable in "Nam” (Royal) posture.

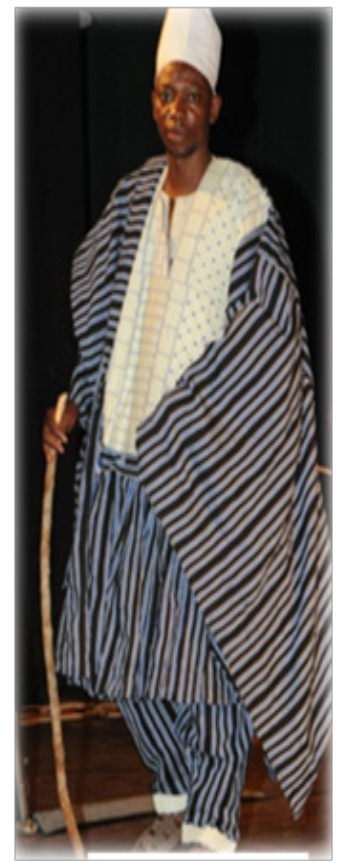

Figure $8 \mathrm{~A}$ man in Yable another posture. 
The funeral Gbagno's fortification is usually done with the talisman and sometimes if one spots any talisman, it may just be one or two. Its powers are hidden. It is important to note that the colour of any Gbagno is dark reddish or dark brownish but they are made from white fabric. The dark reddish or brownish colour is due to the charms that it has been bathed in and sometimes buried in the ground for some number of days or weeks to complete the fortification rites. It should be noted that Gbagno is a general term for anything that is supposed to protect the wearer. An interviewee responding to a question said a Gbagno is a belt made from white fabric that is worn around the waist and hidden from outside view. He continued to state that there are some that comes in the form of triangular underwear (Kpalan-nyircho) with strings for fastening. One can also have a Gbagno in the form of a hat (supur-Gbagno) that is worn on the head. Gbano is not a dress that can be purchased on the open market; it has to be requested for by special offer, usually starting from the spiritualist who would do the fortification (Figure 11).

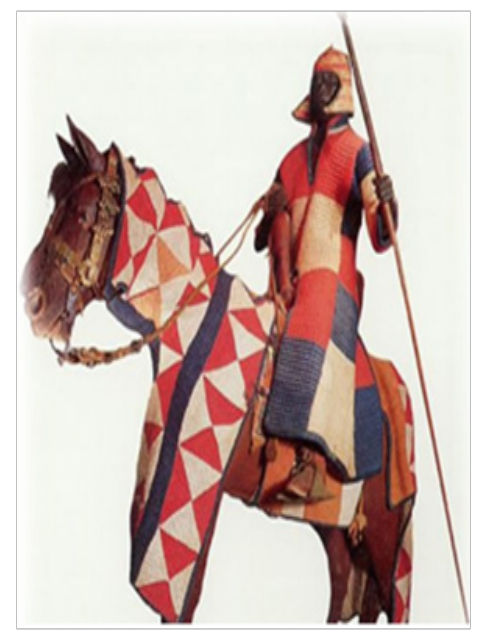

Figure 9 Sculptured rendition of Balmaasu. Source: Liverpool Museum photo gallery.

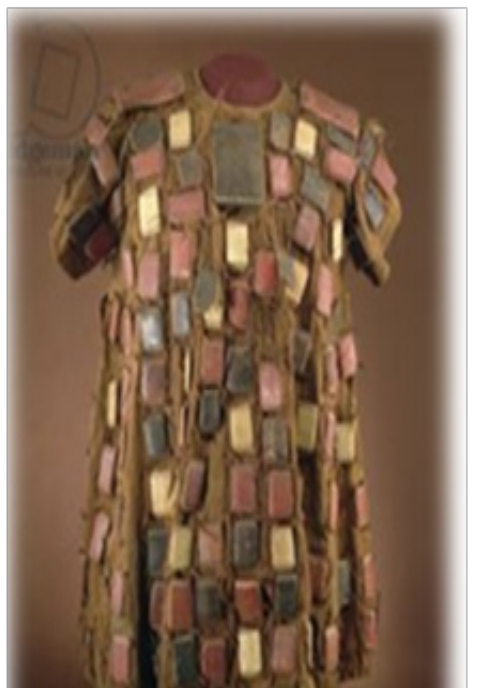

Figure 10 War/Funeral dress (Gbagno).

Kparugu/kpargu/batakari: This gown is of Hausa origin and adopted by the Dagombas and the Moslem community. Now it has been adopted by all in Ghana as a special occasion wear. Kpargu is a long gown with extended broad sleeves which cover the whole length of the arms. The length of the gown itself almost sweeps the floor and normally comes with rich and beautiful, embroidery. Traditionally, there are two types of Kpargu. Nam-Kpargu and ordinary Kapargu.

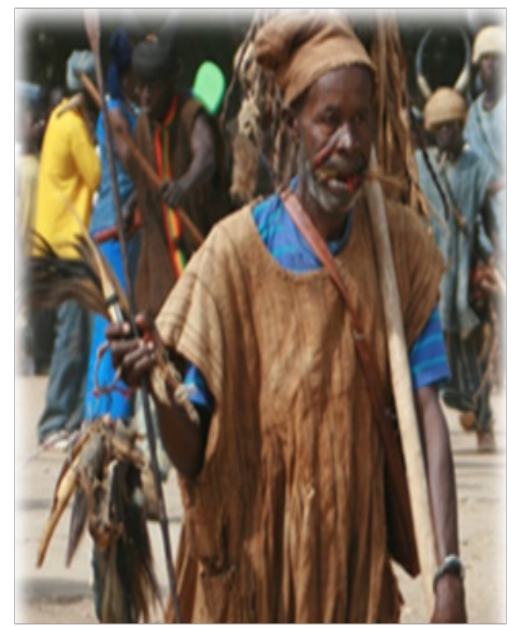

Figure II Funeral Gbagno Source: Getty images.

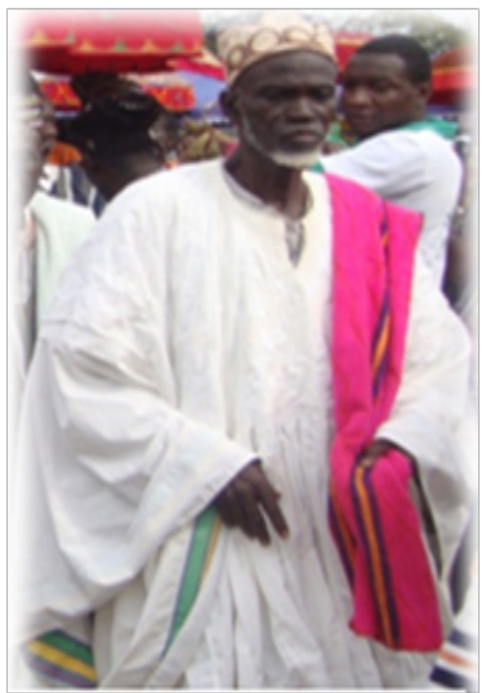

Figure $12 \mathrm{~A}$ chief in Nam Kpargu.

\section{A. Nam-kpargu}

Nam-Kpargu is purely a ceremonial gown sewn from plain white fabric without any pleats at all. It is just a long gown with no decorations or embroidery what so ever. It serves two main purposes;

i. It elevates a person from an ordinary person or prince into the Nam (Chiefdom).

ii. Used as the burial shroud of a deceased chief. It is important to note that one cannot purchase this type of gown in the open market. It is ordered only when an individual is about to be enskined a chief. It therefore becomes part of the accoutrements that are gathered when a person is to be enskined a chief and is handed over to the authority that would confer the title on him. It is usually very expensive since every aspect of it is made by hand without the aid of a machine. Once it is embroiled, it ceases to be a Nam Kpargu. The Nam-Kpaargu is very important in Da- 
gbon tradition where status is a very important issue worn only on two occasions; it is worn when he is elevated in the first instance and on the occasion of his death when it is used as a burial shroud. However the same Nam-Kpargu can be used on another or other elevation occasions when the chief moves up the ladder of the Nam on his way to his optimum title on his line of Nam. However, if the Naa (Chief) can afford, he can provide different Nam-Kpargu on every occasion, in that case, the previous Nam-Kpargu can be worn as a casual wear and can then be embroidered and the loose ends down can be stitched together or put aside to be worn by his grandchildren during his funeral celebrations especially the "Yaawun-Gbaglana" (the grand heir) (Figure 12).

\section{B. Ordinary kpargu}

The ordinary Kpargu on the other hand has embroidery around the neck, the front pockets and at the back. Usually the decorations are at the choice of the wearer. This type of Kpargu can be made from any fabric. The sleeves are supposed to be folded over the shoulders unlike the Nam-kpargu. A good and experienced user would not use the right hand to fold the hands on the left shoulder or vice versa. You are supposed to use the same hand for the folding on the same side of the body. As a fashionable wear, it is not supposed to be worn alone, but a jumper either with long sleeves or short sleeves with pantaloons giving it a three piece outfit dress. The Kpargu used to be the preserve of Dagombas and the Moslem community; it has now assumed a national character which is worn on special or festive occasions. When it assumes the three-piece status, then it is referred to as Batakari. A Batakari is therefore a Kpargu with a jumper which has a closed neck, locked vertically with two to four bottoms and a type of trouser or pantaloons to match. It is, mostly, worn on special or festive occasions such as visiting in-laws, for Friday's prayers, "Eid" (such as Ramadan or Hajj) festivals or attending social or political gatherings. Even though the gown still maintains its traditional significance it is now essentially the question of affordability and not the preserve of any particular group of person or persons (Figure 13).

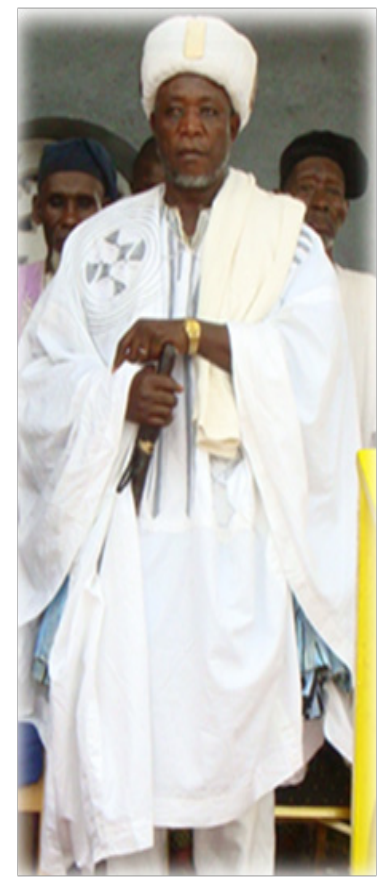

Figure 13 Ordinary kpargu.
Zalabiya/zalabia: Zalabia has more religious connotations than Culture in Dagbon. As a dress, it is like a Priest's cassock, and is used for prayers. It is normally very long from the shoulders to a little below the ankles. It has very long sleeves that extend to the wrists and are bottomed tight to the neck, is Chinese-styled, with buttons to fit. The pockets are slit vertically from the sides. The Zalabia normally does not have any embroidery and usually may be made from lighter materials such as cotton, silk or polyester.

Zaba//kaftan: Zaba is a smaller version of a Zalabia. Its length is shorter just below the knees and the sleeves are also shorter just below the elbows. The pockets are also horizontally slit. Traditionally it does not have embroidery, but due to changing fashion trends, it is now embroidered. Sometimes the sleeves are also long, but loose at the ends without buttons. The Kaftan is a longer version of the Zaba with length down to the feet and the sleeve down to the wrist. The Zaba may be given a collar and splatted slightly at the front with four buttons to fit and like the Zalabia it is made from light material such as polyester, cotton, silk, viscose for the wearers' convenience. However, occasionally thicker or heavier materials such as khaki or wool are preferred by farmers and Fulani's in the north. It usually has slits at the ends downwards to make movement very easy. It is a dress that is worn casually from sunrise to sunset. Originally a Muslim dress, it has assumed a national character, especially by politicians and those who can afford it on festive occasions.

\section{Pantaloons and pants (kpalanga)}

Kurugu: Kurugu by design is a voluminous local trouser usually sewn from several yards of smock fabric which reaches to the ankles. Due to the quantity of fabric used, the middle section naturally creates heavy gathers which sometimes comes to touching the ground in some cases. The legs at the ends are sewn close and fitting to allow trucking into the local boots "(Mugri)" to match. 87\% of the total respondents made up of the Traditional Rulers, Producers and the General Public were of the view that Kurugu is a royal traditional wear and for the high in Dagbon society. But the remaining 13\% made up of the distributors suggested that due to social changes brought about by wealth and education, it is now worn by anyone who can afford it. But they all agreed that it is used on festive occasions and must always be worn by the user in a three - Piece Smock; i.e. the Yensichi, Bingmaa plus either Kpakoto or Yebli to match plus local leather boots. In that traditional "attire" one is considered "properly dressed". When walking, the gathers move like a giant pendulum hanging from one's legs and when used in dancing, one has to be very careful not to step on any side of it, or one may fall. In such a complete outfit, the wearer is not always in hurry and therefore walks majestically that shows its beauty. Sometimes the ends of the legs can be embroidered. Due to its voluminous nature light fabric are mostly used in its production (Figure 14).

Ginjamlani/gingalane (hernia trousers): Ginjamlani can be said to be a smaller version of the Kurugu which is most favoured by dancers. This was also agreed upon by $100 \%$ of the respondents. It is therefore used as a casual wear by the nobility in the compound, or when attending less important calls without the heavy smocks to match. One can wear it without the boots, in this way it is usually preferred for relaxation purposes. By design, it has less gathers, so the pendulum reaches downwards to only around the knees. The legs are slimmer and longer and more often embroidered. It is sometimes referred to as "Talli-Naa" in reference to the chief who made it popular - Alhaji Naa Yakubu Talli, the late Chief of Tolon and former Ghana Ambassador 
to Liberia and Presidential Running mate of Mr Victor Owusu of Popular Front Party in the 1979 General Elections.

Tobalagi: Tobalagi is a smaller version of Ginjamlani; the designs are of the same style except that tobalagi is shorter in length. The length of the legs ends at the knees or a little below the knees. This is to give ease of Movement and is preferred by the elderly. It is a more casual costume by purpose and hence very suitable for the office and less important places. Tobalagi is usually made from local woven fabric unlike the Kurugu and Ginjamalani which are normally made from, lighter material. Tobalagi is more favoured by the Mamprusis in the Northern region than any other ethnic group. This is according to all the 150 respondents.

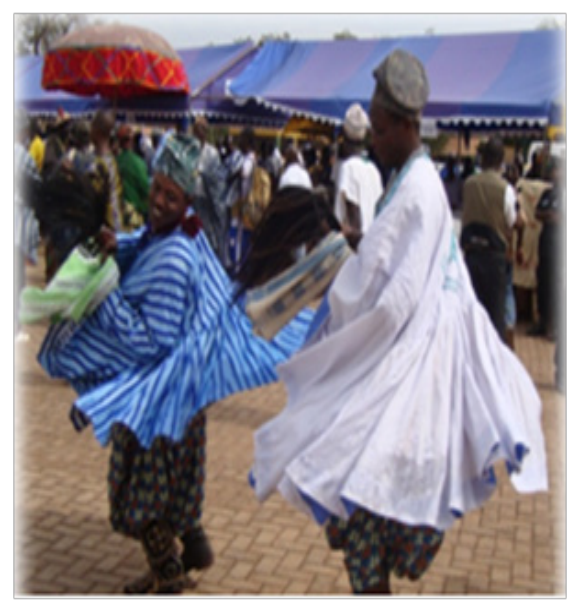

Figure I 4 Men's in Kurugu.

Kpalan-nyiricho: Kpalan-Nyiricho is a unique kind of male local underwear, usually worn by old men within the courtyard for maximum relaxation and fresh air. It is worn mostly during the hot season. By design, it is cut like an isosceles triangle from any type of fabric with elongated straps at the three ends. It is worn by tying the two ends of the base around the waist, the third end is passed between the legs and wrapped around the waist thus assuming the shape of an underpants. This type of pant only covers the front while the buttocks are bare. This type of pants is mostly favoured by older men who are not very active anymore and may only be working around the house or taking care of their grandchildren or great grandchildren while their parents are out on the farm or the women fetching firewood. The most fabric, usually used are flour sacks and light smock fabric. This was specifically attested to by the Traditional Rulers representing 40 respondents out of the total respondents of 150 .

Kpalan-bandeli/kpalan gandeli (peoto): Kpalan-Bandeli or Kpanlan-Gendeli most commonly called "Peoto" is another version of the local under wears, especially in terms of design but not in function. It is a U-shaped thus having a wider, lower section and specifically worn on the farm during work. When machine made, it has no strings at the ends. However when using local fabric and handmade, it is rectangular in shape with strings at both ends which is used to tie the loose ends around the waist. The idea is to give the farmer the freedom of movement, especially when game springs up. This type covers the whole buttocks so that the wearer's private parts are not unduly exposed when he bends down. It can also be worn in the house by the grownups to facilitate easy movement, thus it can be equated to the present day shorts. These assertions were made by the Traditional Rulers, the Producers and the General public representing $87 \%$ of the total Respondents.

\section{Communicating with headgears/hats ("zugprisi”)}

The respondents representing about $87 \%$ made up of the Traditional Rulers, Producers and the General Public posit that traditionally in Dagbon, wearing a smock or a pantaloons needs headgear/hat to send further communication outwards. The non-verbal communication is done through the headgears or hats ("zugprigu"). No one wears a smock without a hat, if one does, it is considered as improper dressing or the person is communicating bereavement. Headgears are an important part of male adornment. Hats are usually made from hand-woven fabric without embroidery, but hand stitched. In dressing, especially for social functions, care must be taken not to offend unintentionally or else, one may be offering one's self as a sitting duck for spiritual target practice if he makes a mistake in the wearing of his hat. It is important to note that there are title hats that must be worn by only the title holders. This is usually red in colour and worn only by chiefs who have reached the highest of their line of elevation. In Dagbon, red is actually a prohibitive colour and only title persons can wear them. The only exception is the Upper East, where it is the preserve of earthly priests (Tindanas) with or without frills. The following are the most acceptable ways of wearing hats and what they communicate in Dagbon. According to all the respondents it is important to note that the communication by hats cut across all the three northern regions, Northern, Upper East and West Regions. Basically, there are three types: the handloom fabric multi-coloured, the sati and the white hat. The following assertions were all collaborated by all the respondents (Figure 15).

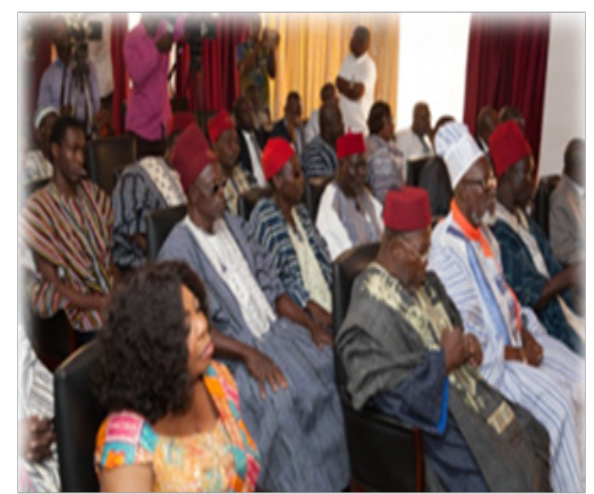

Figure 15 Group of Dagbon Chiefs/Elders paying a curtsey call on President Mahama.

Nkpei-kan or sobigarima: This is the traditional message one gives when he bends or brushes the top of his hat towards the front. In such position, one is throwing a challenge to all around. Literally Nkpeikani or Sobigarima means "I have no equal around". So depending on the social environment, the provocative behaviour might be interpreted to mean either one is the richest and strongest (physically or spiritually), the most handsome or the most knowledgeable. To all interests and purposes, anyone who does that is a rascal, either looking for trouble or one who knows he can excel or win when trouble comes. Traditionally, this type of person if he drinks could get himself poisoned through drink, especially the local brewed pito by his challengers or enemies by keeping poison in the fingernail of the right thumb and dipping the finger in the drink after taking some sips from the calabash as a good will gesture. One could also be challenged physically or spiritually if those around feels offended by his actions. It is a position to avoid unless one is also so fortified spiritually (Figure 16). 
N-laala or N-nyala ntarima: Accurately, it means I am a "peace loving guy" or I don't want to be bothered or leave me alone. As the name implies, the wearer who brushes or bends his hat sideward by the ears either left or right sideward communicates the same message. It is most cherished by the youth and the middle aged. This is the standard form of headgear in Dagbon (Figure 17).

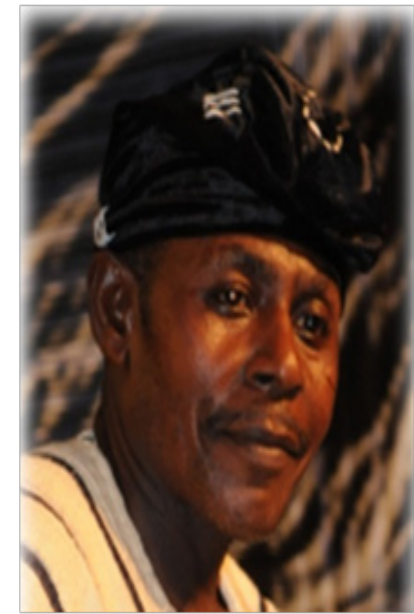

Figure 16 Headgear in Sobigarima posture.

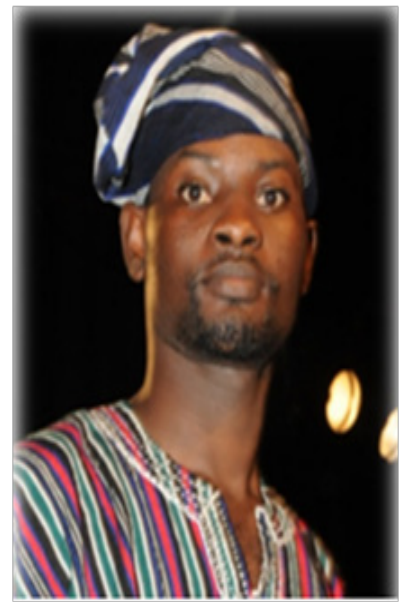

Figure 17 Headgear in N-laala posture.

N-nyanga-behind me/my back: Here the wearer brushes or bends the hat behind him instead of side wards or in front. This is favoured by elderly men, which communicates the message that all that happened was due to his absence. This is to imply that as a responsible person, he would have made a difference to forestall any kind of mishap or disaster, if he had been around. Usually such people are landlords, bread winners or opinion leaders within their families. It also can mean forgiveness "let us put the past behind us" (Figure 18).

N-monikuyagma ("Molfe"): This is a special white hat conical in shape and hand sewn and is worn pointing to the sky. This is worn by very responsible people who traditionally, one can say have "selfactualized". It symbolizes a heavy responsibility. These are people who traditionally are heads of their families, usually have a large kraal, a big compound house or many houses under his control in the community, has at least four wives, many children, a barn full of grains, may have a corn-mill, a tractor, by Dagbon standards a wealthy man and also a philanthropist. It signifies no burden can overcome him. Literally, it means no one goes hungry in my household. In Dagbon these are the people who are allowed to drink and would speak the truth, even when a dagger is on their throat or a gun pointed at their head at the Chief's palace. They are the types who become ancestors when they die and are always remembered by family members and their names mentioned when sacrifices are made within their families. No one dare point a finger at them within the community, they also do not speak at will unless their opinion is sort and most often their contributions become final. In Dagbon it is the preserve of Divisional Chiefdom upwards. Many would have noticed a lot about this kind of hat being worn by the Yaa-Naa. It symbolizes that one has a large following a big responsibility, in fact it symbolizes "carrying". Any prince of Dagbon intending to climb up the ladder within the hierarchy of Chiefdom does not wear the molffe. However, nowadays its status is being abused by young men, especially in Tamale during social occasions such as weddings and on festive occasions (Figure 19).

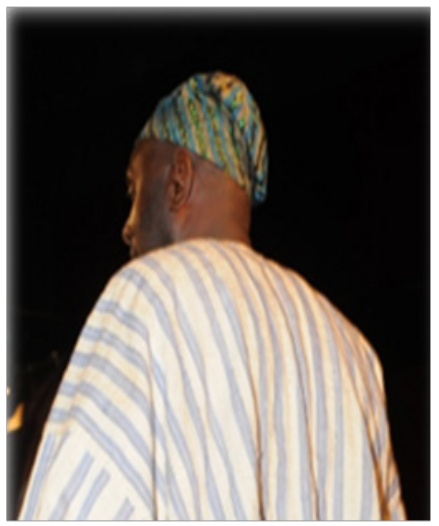

Figure 18 Headgear in N-nyanga posture.

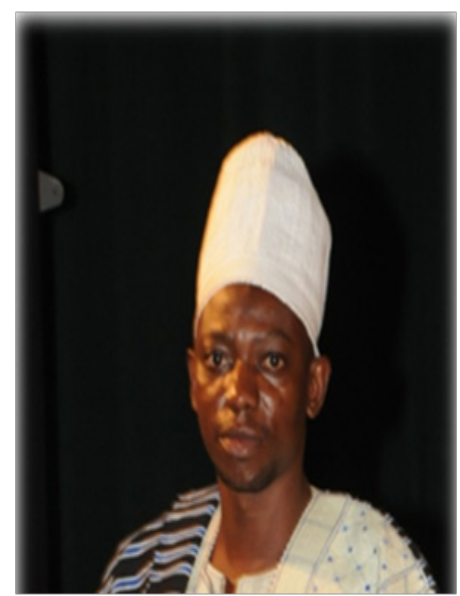

Figure 19 Headgear in Molfe posture.

Aago suprigu: This hat is sewn like the traditional hand looms multicoloured fabric, but made from satin. It is worn like any other hat and the message it communicates also depend on the position, it is brushed or bent towards. However, it used to be the preserve of the most economically endowed since it was more expensive than the local hand woven fabric. Now it is cheap due to the fact that it is gotten from second-hand clothing and turned into hats. It is usually hand decorated, the patterns or colour made according to taste. The most common ones are black in colour.

Boodua (Towel): One would usually see people with towels on their heads as a form of headdress frequently; this is a sign of bereavement. The wearer is mourning the death of a chief and until the final rites 
are performed all mourners would be dressing this way. It is normally rolled over the head while others would knot it up like hats to enable them remove it and wear it with ease. How one wears it is a matter of choice. In Dagbon the towel is only worn as a sign of bereavement and cannot or should not be worn for the pleasure of fashion, anybody who understands the culture would not do that. However draping the towel over a smock is an accepted dress code which has become part of Northern regalia. It is normally used to wipe sweat due to the heat from the sun. It also serves the purpose of being used to accept appreciation fees when dancing to avoid taking "bad money" from enemies who may use the occasion to get "nearer" the wearer (Figure 20).

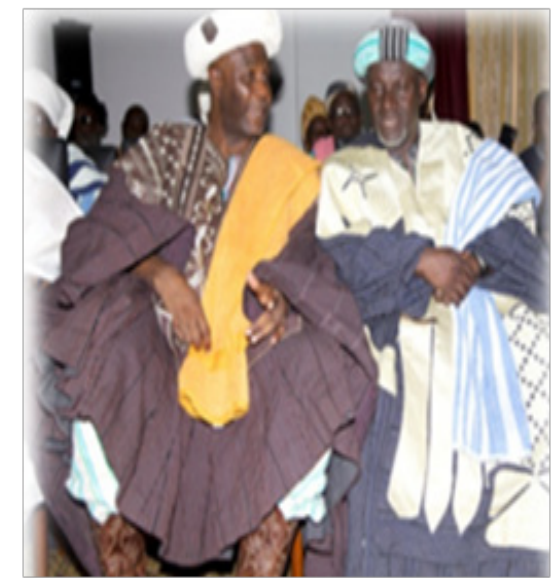

Figure 20 Chiefs displaying Boodua.

Bugu: It is a type of headgear made from the bark of a tree and shaped in the form of a cylinder with an opening at the top. It is worn mainly by regents and mourners. Buri (Plural of Bugu) comes in different shades and sizes. The regent and first daughters would wear theirs long and big. The regent and first daughter would normally have talismans attached to theirs. This is expected to protect them from evil spirits and enemies. It can sometimes be in the form of very big crown-like rings worn down the base of the head. Other members of the bereaved family may wear smaller ones. Some Buri may be made from cardboard. The grand children or the first grandson normally wears them. This is a comic relief within the mourning family when such children are supposed to imitate the deceased (member) so that the funerals are not turned solely into a solemn occasion. In effect they are a solace to the family.

Supri-gbagno: It is a headgear made from the multi-coloured local fabric fortified to provide protection for the wearer. It is usually made from the white fabric or the Kpankobgu (fabric made from guinea fowl feathers). It serves the same purpose as the Gbagno and is usually worn occasionally for serious businesses, especially in times of tension or conflict (Figure 21).

\section{Smock as a symbol of wealth, political and religious power}

A traditional dress refers to a textile which is peculiar to or characteristic of a certain district, country, or ethnic group; retaining strong elements of the culture from which it originates. ${ }^{7}$ It is usually a visible symbolic expression of the belief system, customs or way of life of a particular group of people that changes within a specified period of time. For example, the smock a traditional dress mainly peculiar to the people of Northern decent, maintained its use and character over a period of time but it experiences imitations in form as well as its uses. Smock is still worn during durbars and other ceremonies like installation of chiefs, funerals, etc. as part of Northern Ghanaian culture or custom. The cultural practices of Northerners handed down from their ancestors have not changed considerably and the smock associated with these practices has seen little changes; rather its uses have been modified to be abreast with modern needs. The story of the smock is not anything new to many Northerners and other Ghanaians as it has been the major traditional dress of Northerners. It is adored, respected and internationally recognized due to its dazzling, patterns of bright colours, geometric shapes, bold designs and ingenious nature. Some smock designs are royal and sacred dress worn mainly in times of extreme importance. The smock was the dress of kings and chiefs. Over time, the use of smock has become more widespread, however, its importance has remained and it is held in high esteem in Northern Ghana and the entire country of Ghana. ${ }^{8}$

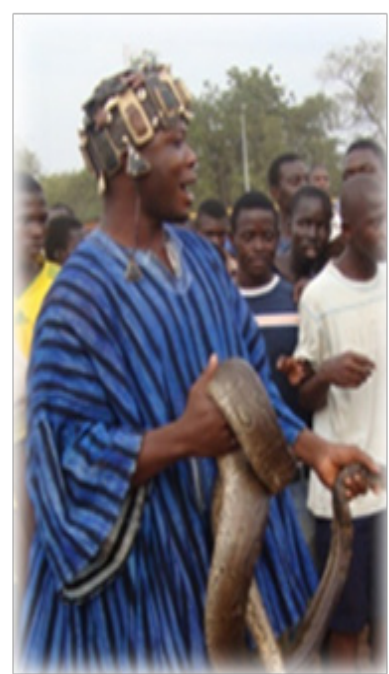

Figure 2I A man in Supri-Gbano.

\section{Conclusion}

Traditional textiles have been and continue to be extremely important to many societies in Ghana especially those in the North as they still reflect much of the social customs, culture and traditions of the people. Some selected smock types were examined to help unearth their aesthetics and significance in the society and the world at large. People from the Northern part of Ghana possess an exceptionally long heritage of communicating their worldview through smocks. Beliefs concerning the social and religious structures of Northerners life have been woven into smock and its fabrics for many years. Northerners use a smock for functional everyday use, but they also embellished some with meaningful geometric shapes and designs representing the mythological ideas of the society to the world. And this clearly supports the claim that the knowledge, and understanding of aesthetics of smock are a positive means of promoting Northern Ghanaian culture in the world and they serve as a way of identifying the people.

\section{Acknowledgments}

None.

\section{Conflict of interest}

Author declares there is no conflict of interest in publishing the article. 


\section{References}

1. Sarpong P. Ghana in retrospect: some aspects of ghanaian culture. 2 nd ed. Tema, Ghana: Ghana Publishing Corporation; 1974. p. 134.

2. Fage JD. Reflections on the early history of the Mossi-Dagomba group of States. Historian in tropical Africa: studies presented and discussed. Africa; 1964. p. 177-191.

3. Staniland M, Iliasu AA. The lions of dagbon: political change in northern ghana. Cambridge University: Unpublished Undergraduate Thesis; 1975. p. 132-136.

4. Akpabli K. Tickling the Ghanaian: Encounters with Contemporary Culture. 1st ed. Accra, Ghana: TREC Publications; 2011. p. 101-108.
5. Adu Akwaboa S. A survey of the Textile Industry in Ghana. UST, Philippines; College of Art: 1976.

6. Tettehfio, Amateye L. The Role of the Indigenous Ghanaian Textile Industry In Relation To the President's Special Initiative (Psi) On. Kwame Nkrumah University of Science and Technology, Ghana; 2009.

7. Asmah EA. Cultural Symbolism in Asante Traditional Textiles. Unpublished thesis. Kwame Nkrumah University of Science and Technology, Ghana; 2009.

8. Essel OQ, Amissah ERK. Smock fashion Culture in Ghana's Dress Identity-Making. Historical Research Letter, Ghana; 2015;18:32-38. 